remains unknown. The novel S: $\Delta 246-252$ deletion and additional mutations in the spike protein should be considered to understand their effects on viral fitness and host interaction. This first report of the SARS-CoV-2 lambda variant in Southern Brazil raises concern regarding a possible dissemination of this lineage in the region. Moreover, considering that this VOI has rapidly spread in Peru, Ecuador, Chile, and Argentina, we believe that this lambda variant has considerable potential to become a VOC.

Supplementary material. To view supplementary material for this article, please visit https://doi.org/10.1017/ice.2021.390

Acknowledgments. We thank the staff of Laboratório de Diagnóstico de SARS-CoV-2 as well as the staff of the Hospital Infection Committee of our institution (Hospital de Clínicas de Porto Alegre) for providing data used in this study. This research was conducted using the Hospital de Clínicas de Porto Alegre Biobank resources (application no. GPPG 2020-0163).

Financial support. This study was funded by FAPERGS (20/2551-0000265-9), National Institute of Antimicrobial Resistance Research - INPRA (MCTI/ CNPq/CAPES/FAPs $n^{\circ}$ 16/2014) and by Fundo de Incentivo a Pesquisa e Eventos do Hospital de Clínicas de Porto Alegre (FIPE/HCPA) (Project no. 2020-0163). P.L.W. and F.C.Z.V. were supported by a grant from the Coordenação de Aperfeiçoamento de Pessoal de Nível Superior (CAPES).

Conflicts of interest. A.P.Z., A.L.B., and A.F.M. are research fellows of the National Council for Scientific and Technological Development (CNPq), Ministry of Science and Technology, Brazil. A.P.Z. has received a research grant from Pfizer unrelated to this work. All other authors have no conflict to declare.

\section{References}

1. Liu Z, Van Blargan LA, Louis-Marie Bloyet, et al. Identification of SARS-CoV-2 spike mutations that attenuate monoclonal and serum antibody neutralization. Cell Host Microbe 2021;29:477-488.
2. Technical report. COVID-19 weekly epidemiological update, edition 44 . World Health Organization website. https://reliefweb.int/sites/reliefweb. int/files/resources/20210615_Weekly_Epi_Update_44.pdf. Published 2021. Accessed June 15, 2021.

3. Pangolin: lineage assignment in an emerging pandemic as an epidemiological tool. [v1.1.21]. Pangolin website. http://pangolin.cog-uk.io/. Published 2021. Accessed June 15, 2021.

4. Latif AA, Mullen JL, Alkuzweny M, et al. C.37 lineage report. Outbreak Info website. https://outbreak.info/situation-reports?pango=C.37. Published 2021. Published June 2021. Accessed June 15, 2021.

5. Tracking of variants. GISAID website. www.gisaid.org/hcov19-variants. Accessed June 15, 2021.

6. Wink PL, Volpato F, de Lima-Morales, et al. RT-qPCR half reaction optimization for the detection of SARS-CoV-2. 1. medRxiv 2021. doi: 10.1101/ 2021.05.19.21257470.

7. Romero PE, Dávila-Barclay A, Gonzáles L, et al. C.37: Novel lineage expanding in Peru and Chile, with a convergent deletion in the ORF1a gene $(\Delta 3675-3677)$ and a novel deletion in the Spike gene $(\Delta 246-252, \mathrm{G} 75 \mathrm{~V}$, T76I, L452Q, F490S, T859N). https://virological.org/t/novel-sublineagewithin-b-1-1-1-currently-expanding-in-peru-and-chile-with-a-convergentdeletion-in-the-orfla-gene-3675-3677-and-a-novel-deletion-in-the-spike-gene246-252-g75v-t76i-1452q-f490s-t859n/685. Published April 2021. Accessed October 20, 2021.

8. INS confirma presencia de variante C-37 del coronavirus en Perú, 25 Mayo 2021. Peru Ministerio de Salud: Instituto Nacional de Salud website. https:// web.ins.gob.pe/index.php/es/prensa/noticia/minsa-ins-confirma-presenciade-variante-c-37-del-coronavirus-en-peru Published 2021. Published 2021. Accessed June 15, 2021.

9. Vigilancia de variantes de SARS-CoV-2 en CABA, Provincia de Buenos Aires, Córdoba, Entre Ríos, Neuquén y Santa Fe. Argentina government website. https://www.argentina.gob.ar/noticias/vigilancia-de-variantes-desars-cov-2-en-caba-provincia-de-buenos-aires-cordoba-entre-rios. Published 2021. Accessed June 15, 2021.

10. Latif AA, Mullen JL, Alkuzweny M, et al. Chile mutation report. Outbreak Info website. https://outbreak.info/location-reports?loc $=$ CHL\&pango $=$ C. 37 . Published 2021. Accessed June 15, 2021.

\title{
Early detection of the SARS-CoV-2 P.1 variant in Rio Grande do Sul, Brazil: a case report
}

\begin{abstract}
Fabiana Caroline Zempulski Volpato $\mathrm{MSc}^{1,2,3}$ (D), Priscila Lamb Wink $\mathrm{PhD}^{1,2,4}$, Francielle Liz Monteiro PhD ${ }^{1,2,5}$, Julia Biz Willig MSc ${ }^{1,2}$, Tarsila Vieceli MD ${ }^{6}$, Andreza Francisco Martins Ph.D, ${ }^{1,4,7,8}$, Alexandre Prehn Zavascki MD, PhD ${ }^{1,6,9}$ and Afonso Luís Barth Ph.D ${ }^{1,2,3,4}$

${ }^{1}$ LABRESIS - Laboratório de Pesquisa em Resistência Bacteriana, Hospital de Clínicas de Porto Alegre, Porto Alegre, Rio Grande do Sul, Brasil, ${ }^{2}$ Laboratório de Diagnóstico de SARS-CoV-2, Hospital de Clínicas de Porto Alegre, Rio Grande do Sul, Brasil, ${ }^{3}$ Programa de Pós-Graduação em Ciências Médicas, Universidade Federal do Rio Grande do Sul, Porto Alegre, Rio Grande do Sul, Brasil, ${ }^{4}$ Programa de Pós-Graduação em Ciências Farmacêuticas, Universidade Federal do Rio Grande do Sul, Porto Alegre, Rio Grande do Sul, Brasil, ${ }^{5}$ Laboratório de Diagnóstico Molecular, Universidade Franciscana, Santa Maria, Rio Grande do Sul, Brasil, ${ }^{6}$ Infectious Diseases Service, Hospital de Clínicas de Porto Alegre, Porto Alegre, Rio Grande do Sul, Brasil, ${ }^{7}$ Bioinformatic Core, Hospital de Clínicas de Porto Alegre, Rio Grande do Sul, Brazil, ${ }^{8}$ Departamento de Microbiologia, Imunologia e Parasitologia, Instituto de Ciências Básicas, Universidade Federal do Rio Grande do Sul, Brasil and ${ }^{9}$ Internal Medicine Department, Universidade Federal do Rio Grande do Sul, Porto Alegre, Rio Grande do Sul, Brazil
\end{abstract}

\footnotetext{
Author for correspondence: Fabiana Caroline Zempulski Volpato, E-mail: fabiana_volpato@yahoo.com.br

Cite this article: Volpato FCZ, et al. (2022). Early detection of the SARS-CoV-2 P.1 variant in Rio Grande do Sul, Brazil: a case report. Infection Control \& Hospital Epidemiology, 43: 1997-1999, https://doi.org/10.1017/ice.2021.387
}

To the Editor-In December 2019, a new coronavirus, severe acute respiratory syndrome coronavirus 2 (SARS-CoV-2), emerged in China and was associated with coronavirus disease 2019 (COVID-19). Since it was first described, multiple lineages of SARS-CoV-2 have been identified worldwide. Due to the increased transmissibility of the new variants, the initially

(c) The Author(s), 2021. Published by Cambridge University Press on behalf of The Society for Healthcare Epidemiology of America. 
dominant lineages B.1.1.28 and B.1.1.33 in 2020 in Brazil have been gradually replaced by the variant of interest (VOI) P.2 and by the variant of concern (VOC) P.1. ${ }^{1}$ The lineage P.1 was first identified in the beginning of December 2020 in Manaus, Amazonas state, Northern Brazil, and it has been associated with a potential higher transmissibility of the virus. ${ }^{1,2}$ In this study, we describe the characteristics of the VOC P.1 from a patient with symptoms in early November 2020 in the Rio Grande do Sul (RS) state, Southern Brazil. This study was approved by the Ethics Committees from Hospital de Clínicas de Porto Alegre (CAAE: 30767420.2.0000.5327).

A middle-aged woman with diabetes mellitus and kidney transplant, a resident of the metropolitan region of Porto Alegre city in Southern Brazil, was admitted to a tertiary-care hospital due to severe COVID-19 on November 29, 2020. The first symptoms of a viral infection were reported 12 days before her hospitalization and included fatigue, dry cough, myalgia, and headache. She had no history of travel and described a direct contact with a person who had been diagnosed with COVID-19 16 days before her admission. The COVID-19 worsened, and the patient ultimately died during hospitalization.

On the day of hospital admission, oro/nasopharyngeal swabs were obtained and a nucleic acid amplification testing was carried out to check for SARS-CoV-2 infection. After RNA extraction, the $\mathrm{N} 1$ and N2 target genes of SARS-CoV-2 were amplified using a set of primers and probes in a real-time reverse transcriptase polymerase chain reaction (RT-qPCR) as described by the US Centers for Disease Control and Prevention (CDC). ${ }^{3}$

As part of genomic surveillance research that was approved by the Ethics Committee from Hospital de Clínicas de Porto Alegre (CAAE: 30767420.2.0000.5327), the RNA of the clinical specimen (164_LABRESIS) was subjected to whole-genome sequencing (WGS). The RNA of the clinical specimen was extracted using QIAamp Viral RNA Mini Kit (QIAGEN GmbH, Hilden, Germany) to obtain a final elution volume of $60 \mu \mathrm{L}$. Sequencing libraries were prepared using the CleanPlex SARS-CoV-2 panel (Paragon Genomics, Hayward, CA) protocol for target enrichment and library preparation according to the manufacturer's instructions (https://www.paragongenomics.com/wp-content/uploads/2020/03/ UG4001-01_-CleanPlex-SARS-CoV-2-Panel-User-Guide.pdf). The resulting libraries were built using an Illumina MiSeq sequencer (Illumina, San Diego, CA). Consensus sequences were generated by the QIASeq SARS-CoV-2 pipeline (QIAGEN CLC Genomics Workbench 21, Germantown, PA) and a high-quality wholegenome sequence was obtained (coverage genome: 99.97\%; reads Q>30: 628,996; size of genome: $29.89 \mathrm{~Kb}$ ). The specimen 164_LABRESIS was classified as the P.1 variant using the Phylogenetic Assignment of Named Global Outbreak Lineages (Pangolin) software tool (version 3.0.2), ${ }^{4}$ and the sequence was deposited into the GISAID database (https://www.gisaid.org/; no. EPI_ISL_3233232).

According to Pangolin, ${ }^{4}$ the VOC P1 is characterized by 17 amino acid changes (including 10 in the spike protein), 3 deletions, 4 synonymous mutations, and one 4-bp nucleotide insertion compared to the most closely related sequence of B.1.1.28 available from April 4, 2020 (GISAID ID: EPI_ ISL_722052). ${ }^{2}$ The P.1 lineage-defining mutations in the spike protein (especially those at the receptor-binding domains [RBDs] $\mathrm{K} 417 \mathrm{~T}, \mathrm{E} 484 \mathrm{~K}$, and $\mathrm{N} 501 \mathrm{Y}$ ) raise concern because they may enhance ACE2 affinity and contribute to antibody evasion. ${ }^{5}$ The specimen 164_LABRESIS presented 13 of the total of mutations characteristics of the VOC P.1 (orflab: S1188L and K1795Q; del: 11288:9; spike: L18F, T20N, D138Y, R190S, K417T, E484K, N501Y and H655Y; orf8: E92K; nucleocapsid: P80R). The isolate 164_LABRESIS has 9 of 10 mutations in the spike protein, including the 3 P.1 lineage-defining mutations associated with the RBD region.

The first description of the VOC P.1 in Brazil occurred in mid- to late December 2020 in Manaus, Amazon state. ${ }^{1}$ According to Faria et $\mathrm{al}^{1}{ }^{1}$ P. 1 comprises $42 \%$ of the genomes sequenced in December 2020 in Northern Brazil. However, this lineage was not found in the specimens collected in November 2020 in the same region. ${ }^{1}$ In Rio Grande do Sul, the first report of the VOC P.1 occurred on January 29, 2021, from a patient hospitalized in Gramado city. ${ }^{6}$ Thereafter, Silva et $\mathrm{al}^{7}$ reported that the P.1 lineage had already been circulating in the state in late November 2020 but was not disseminated among individuals in the region. The identification of 164_LABRESIS confirms the presence of the VOC P.1 at least in mid-November 2020 in Rio Grande do Sul, according to the onset of symptoms reported 12 days before admission. These findings suggest that the P.1 variant could already have been circulating in Rio Grande do Sul before becoming increasing prevalent in the region. Notably, the predominance of the VOC P.1 in Porto Alegre was documented only in February 2021, when this lineage was associated with a rapid increase in hospitalization rates in the region. ${ }^{8}$

Our findings suggest that the VOC P.1 in a specimen from a patient infected in early November 2020 could already have been circulating in Southern Brazil at least 3 months before the increased predominance of this lineage. In fact, genomic surveillance is a fundamental tool for understanding the evolution and spread of SARS-CoV-2 variants.

Acknowledgments. We thank the staff of Laboratório de Diagnóstico de SARS-CoV-2 as well as the staff of the Hospital Infection Committee of our institution, Hospital de Clínicas de Porto Alegre, for providing the data used in this study.

Financial support. This study was funded by FAPERGS (20/2551-0000265-9), National Institute of Antimicrobial Resistance Research - INPRA (MCTI/CNPq/ CAPES/FAPs n ${ }^{\circ} 16 / 2014$ ) and by Fundo de Incentivo a Pesquisa e Eventos do Hospital de Clínicas de Porto Alegre (FIPE/HCPA project no. 2020-0163). PLW and FCZV were supported by a grant from the Coordenação de Aperfeiçoamento de Pessoal de Nível Superior (CAPES).

Conflicts of interest. A.P.Z., A.L.B., and A.F.M. are research fellows of the National Council for Scientific and Technological Development (CNPq), Ministry of Science and Technology, Brazil. APZ has received a research grant from Pfizer not related to this work. All other authors have no conflicts to declare.

\section{References}

1. Naveca FG, Nascimento V, de Souza VC, et al. COVID-19 in Amazonas Brazil, was driven by the persistence of endemic lineages and P.1 emergence. Nat Med 2021. doi: 10.1038/s41591-021-01378-7.

2. Faria NR, Mellan TA, Whittaker C, et al. Genomics and epidemiology of the P.1 SARS-CoV-2 lineage in Manaus, Brazil. Science 2021;372: 815-821.

3. Centers for Disease Control and Prevention, Respiratory Viruses Branch, Division of Viral Diseases. Real-time RT-PCR panel for detection 2019 novel coronavirus. 2020. US Food and Drug Administration website. https://www. fda.gov/media/134922/download. Accessed August 26, 2021.

4. Pangolin: lineage assignment in an emerging pandemic as an epidemiological tool. [v3.0.2]. Pangolin website. http://pangolin.cog-uk.io/. Accessed August 26, 2021.

5. Dejnirattisai W, Zhou D, Supasa $\mathrm{P}$, et al. Antibody evasion by the Brazilian P.1 strain of SARS-CoV-2. Biorxiv 2021. doi: 10.1101/2021.03.12.435194. 
6. Salvato RS, Gregianini TS, Campos AAS, et al. Epidemiological investigation reveals local transmission of SARS-CoV-2 lineage P.1 in Southern Brazil. Res Sq 2021. doi: 10.21203/rs.3.rs-280297/v1.

7. Silva MS, Demoliner M, Hansen AW, et al. Early detection of SARS-CoV-2 P.1 variant in Southern Brazil and reinfection of the same patient by P.2. Res Sq 2021. doi: 10.21203/rs.3.rs-435535/v2.
8. Martins AF, Zavascki AP, Wink PL, et al. Detection of SARS-CoV-2 lineage P.1 in patients from a region with exponentially increasing hospitalisation rate, February 2021, Rio Grande do Sul, Southern Brazil. Euro Surveill 2021;26:2100276.

\title{
How human behavior will lead to the next pandemic
}

\author{
Nikolaos Mazonakis MD ${ }^{1}$, loulia Markaki MD² and Nikolaos Spernovasilis MD, MPH ${ }^{1}$ (]) \\ ${ }^{1}$ School of Medicine, University of Crete, Heraklion, Greece and "'Sotiria" General Hospital for Thoracic Diseases, Athens, Greece
}

To the Editor-Since the outbreak of coronavirus disease 2019 (COVID-19), scientists have been pondering over the causative factors that are essential for infectious diseases to emerge. Many interpret pandemics solely as the result of the expanding human population, but this may be a half truth. The overall choices we make on a political, socioeconomic, and personal level determine the likelihood of the next outbreak to occur (Fig. 1). The major epidemic and pandemic outbreaks of the last few decades were caused by zoonoses. Zoonotic species, especially viruses and protozoa, are twice as likely to emerge in comparison to nonzoonotic species. ${ }^{1}$ Continuous interactions between humans and wild animals increase the risk of emerging diseases. A study in the AsianAustralasian region revealed that those wild mammals that predominantly harbor emerging pathogens are 15 times more likely to use a human modified environment compared to other wild mammals in the same region. ${ }^{2} \mathrm{~A}$ typical case of this human-animal interface is bushmeat hunting for human consumption, which not only leads to species extinction but also promotes transmission of previously unknown infectious agents to humans. ${ }^{3}$ Urban wildlife markets are present in many parts of the world, creating pathways for zoonotic diseases to thrive. For example, the probable origin of COVID-19 was a wildlife market in the city of Wuhan, China. ${ }^{4}$ Illegal wildlife trade, a profitable business with tremendous financial interests, increases human exposure to wildlife vectors, resulting in the emergence of infectious diseases. ${ }^{5}$ All of these factors reflect the human greed and ceaseless need for intervention in ecosystems with a single purpose, human benefit.

Apart from wildlife trade, deforestation also brings humans closer to the wild and opens the gate for the spread of emerging diseases. Urbanization, land use for industrial farming, monocul-

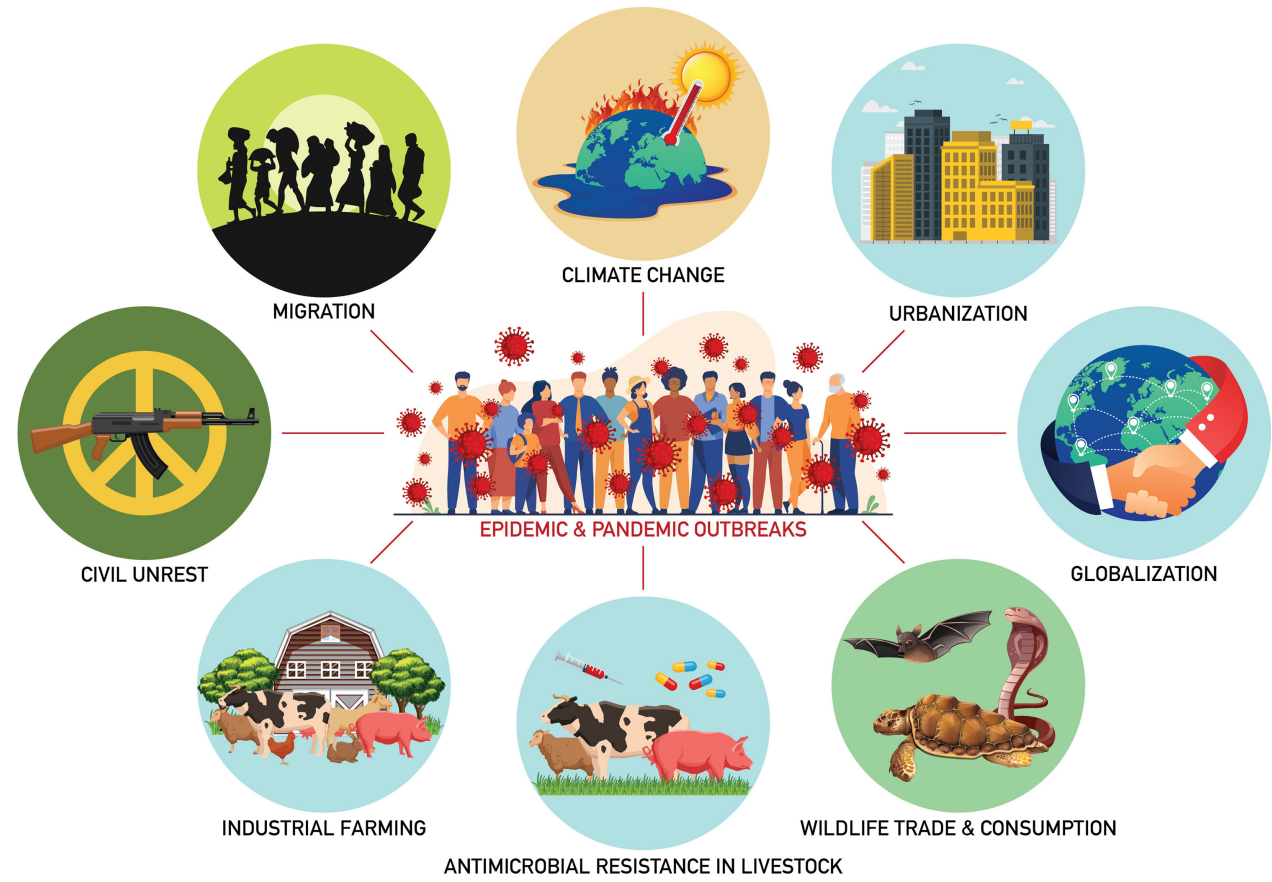

Fig. 1. Major drivers of the emergence of epidemics and pandemics.
Author for correspondence: Nikolaos Spernovasilis, E-mail: nikspe@hotmail.com Cite this article: Mazonakis N, Markaki I, and Spernovasilis N. (2022). How human behavior will lead to the next pandemic. Infection Control \& Hospital Epidemiology, 43: 1999-2000, https://doi.org/10.1017/ice.2021.455 ture tree plantations, especially for the production of palm oil, and wildfires, which are increasing exponentially due to global warming, all lead to habitat and biodiversity loss. ${ }^{6}$ This ultimately results in pathogen spillover from wildlife to domestic animals and 